\title{
Inhibitors of Cyclic Nucleotide Phosphodiesterase Isozymes Type-III and Type-IV Suppress Mitogenesis of Rat Mesangial Cells
}

Karel Matousovic, Joseph P. Grande, Claudia C. S. Chini, Eduardo N. Chini, and Thomas P. Dousa

Nephrology Research Unit, Division of Nephrology and Internal Medicine, Departments of Medicine, Physiology and

Laboratory Medicine, Mayo Clinic and Foundation, Mayo Medical School, Rochester, Minnesota 55905

\begin{abstract}
We studied interactions between the mitogen-activated protein kinase (MAPK) signalling pathway and cAMP-protein kinase (PKA) signaling pathway in regulation of mitogenesis of mesangial cells (MC) determined by $\left[{ }^{3} \mathrm{H}\right.$ ] thymidine incorporation, with or without added EGF. Forskolin or dibutyryl cAMP strongly (by 60-70\%) inhibited $\left[{ }^{3} \mathrm{H}\right]-$ thymidine incorporation into MC. Cilostamide, lixazinone or cilostazol selective inhibitors of cAMP-phosphodiesterase (PDE) isozyme PDE-III, inhibited mitogenesis to similar extent as forskolin and DBcAMP and activated in situ PKA, but without detectable increase in cAMP levels. Cilostamide and cilostazol were more than three times more effective at inhibiting mesangial mitogenesis than rolipram and denbufylline, inhibitors of isozyme PDE-IV, even though PDE-IV was two times more abundant in MC than was PDE-III. On the other hand, when incubated with forskolin, rolipramenhanced cAMP accumulation was far greater (10-100 $\times)$ than with cilostamide. EGF increased MAPK activity $(+300 \%)$; PDE isozyme inhibitors which suppressed mitogenesis also inhibited MAPK. PDE isozyme inhibitors also suppressed PDGF-stimulated MC proliferation. We conclude that cAMP inhibits the mitogen-dependent MAPKsignaling pathway probably by decreasing the activity of Raf-1 due to PKA-catalyzed phosphorylation. Further, we surmise that minor increase in the cAMP pool metabolized by PDE-III is intimately related to regulation of mesangial proliferation. Thus, PDE isozyme inhibitors have the potential to suppress MC proliferation by a focused effect upon signaling pathways. (J. Clin. Invest. 1995. 96:401-410.) Key words: cAMP-dependent protein kinase $\bullet$ cilostamide • rolipram • epidermal growth factor $\bullet$ mitogen-activated
\end{abstract}

Address correspondence to Thomas P. Dousa, M.D., 921B Guggenheim Bldg., Mayo Clinic, Rochester, MN 55905. Phone: 507-284-4343; FAX: 507-284-8566.

Received for publication 29 August 1994 and accepted in revised form 20 March 1995.

1. Abbreviations used in this paper: $\mathrm{B}_{2}$-cAMP, dibutyryl cAMP; MBP, myelin basic protein; cAMP-PDE, any PDE activity using cAMP as substrate; cGMP-PDE, any PDE activity using cGMP as substrate; MAPK, mitogen activated protein kinase; PDE, cyclic- $3^{\prime}, 5^{\prime}$-nucleotide phosphodiesterase in general; PKA, protein kinase A; MC, mesangial cell (s).

J. Clin. Invest.

(C) The American Society for Clinical Investigation, Inc.

0021-9738/95/07/0401/10\$2.00

Volume 96, July 1995, 401-410 protein kinase (MAPK) • isozymes - cAMP-phosphodiesterase

\section{Introduction}

The accelerated proliferation of glomerular mesangial cells (MC) ${ }^{1}$ is a common feature of the many glomerular diseases (1-3). The cell cycle of MC is under the influence of a large number of humoral autocrine and/or paracrine factors which either promote or suppress mitogenesis and cell proliferation (1-4). In certain glomerulopathies some of these autocrine factors are produced in high quantity by stimulated MC (1-4). Moreover, in the case of infiltrative glomerular lesions, large quantity of mitogens are also generated by invading inflammatory cells $(1,3,5)$. Understanding of the signal transduction systems by which these humoral factors modulate the rate of MC proliferation is essential for rational design of novel pharmacotherapeutic approaches aimed to suppress the excessive proliferation of $\mathrm{MC}$ in glomerular diseases.

Recent observations established that some growth factors and cytokines stimulate the mitotic synthesis of DNA and cell proliferation by activation of the so-called mitogen-activated protein kinase (MAPK) phosphorylation cascade $(6,7)$. This signaling pathway (details of which are outlined in recent reviews) $(6-10)$ is initiated by mitogen binding to its receptor, tyrosine phosphorylations, which is followed by interactions of "small adaptor proteins" which promote conversion of membrane-anchored Ras-GDP to active form Ras-GTP $(11,12)$. Active Ras-GTP then promotes translocation of a protooncogene-coded protein Raf-1 from cytoplasm to the membrane, which results in activation of the protein kinase moiety of Raf-1 (13). The Raf-1 is first the protein kinase $(6,7,9)$ which activates by phosphorylation another protein kinase (MEK or MAPKK), which in turn ultimately activates the key enzyme of the cascade the mitogen activated protein kinase (MAPK). Then, activation of Raf-1 protein kinase initiates a sequence of protein phosphorylations which ultimately leads to activation of MAPK, which then triggers mitotic DNA synthesis and initiates the cell replication cycle $(6,7,10)$, via proline-directed phosphorylation of nuclear transcription factors of immediate early genes (9).

Several investigators found recently that in some cell types the mitogen-activated MAPK phosphorylation cascade and stimulation of cell proliferation by growth factors/cytokines can be inhibited by "crosstalk" with another signaling system $(12,14-17)$ the cAMP-activated protein kinase (PKA). According to current evidence, when CAMP-activated PKA phosphorylates $\mathrm{Ser}^{43}$ in the regulatory domain of the Raf-1 molecule (16), the protein kinase activity in the catalytic domain of Raf-1 is inhibited. Since Raf-1 protein kinase initiates the whole cascade of phosphorylations, its inhibition ultimately prevents 
activation of MAPK and inhibits mitogenesis (11-17). In studies of nonrenal cell types (12) the cAMP-PKA pathway was activated by potent stimuli of adenylate cyclase such as forskolin (14) or cholera toxin (15), or by high doses of hormonal agonists of adenylate cyclase (15). All of these stimuli of adenylate cyclase caused considerable accumulation of cAMP which, in turn, elicited marked inhibition of proliferation of smooth muscle cells (14), adipocytes (15), or of fibroblasts $(16,17)$. However, in a number of other cell types, such as PC12 cell line of neural origin (18), thyroid cells, and others (19), the enhanced levels of cAMP stimulated rather than inhibited activity of MAPK and promoted cell growth and differentiation $(18,19)$

In our preceding study of isolated rat glomeruli we observed that antagonists of some isozymes of cyclic- $3^{\prime}, 5^{\prime}$-nucleotide phosphodiesterases (PDE), ${ }^{2}$ mainly PDE-IV (22), in very low concentrations suppress the generation of endogenous reactive oxygen metabolites via activation of PKA but without measurable increase in cAMP content. These observations suggested to us that decreased turnover of a cAMP pool, which is controlled by a specific PDE isozyme(s), can activate cAMP-PKA pathway without stimulation of adenylate cyclase and without significant change of measurable cAMP content (22).

In view of these observations (22) and reports of inhibitory crosstalk of cAMP-PKA with the MAPK-signaling pathway (12) from studies of nonrenal tissues (14-17), we investigated which PDE isozymes are present and prevalent in rat glomerular MC and then we examined whether selective inhibition of PDE isozyme (s) would cause activation of the cAMP-PKA pathway (22) and thereby result in crosstalk inhibition (12) of MC proliferation, either in the ambient state or in cells stimulated by mitogens.

\section{Methods}

MC preparation and culture. Glomeruli were isolated from 200-gram male Sprague-Dawley rats by differential sieving, as previously described (35). Cell outgrowths were characterized as MC by positive immunohistochemical staining for vimentin, smooth muscle-specific actin, and negative stains for cytokeratins, factor VIII-related antigen, and leukocyte common antigen (antibodies from Dako Corp., Carpinteria, CA). Cells used in experiments were from 4-10 passages and completely homogenous MC according above mentioned criteria. Rat MC were plated in 150-mm culture dishes in complete Waymouth's medium (Waymouth's medium supplemented with $20 \%$ heat-inacti-

2. In this report, the PDE isozymes are classified as proposed by Dr. J. A. Beavo $(20,21)$. According to this nomenclature, PDE-I is the family (also called "type") of PDE isozymes dependent on ionized calcium $\left(\mathrm{Ca}^{2+}\right)$ and calmodulin (CaM); PDE-II is family of isozymes cAMP-PDE activity of which is stimulated by low ( $\mu \mathrm{M}$ range) concentration of cGMP; the PDE-III are isozymes with low $K_{\mathrm{m}}$ for cAMP and are sensitive to inhibition by cilostamide, "cardiotonic inhibitors" and cGMP; PDE-IV are isozymes with very high affinity and selectivity for cAMP, are selectively inhibited by rolipram, RO-20-1724 and denbufylline; PDE-V are those isozymes which selectively hydrolyze only cGMP independent of $\mathrm{Ca}^{2+} / \mathrm{CaM}$; bind allosterically cGMP, and are present in somatic cells; PDE-VI is selective cGMP-PDE which is uniquely localized in photoreceptor and interacts with GTP-binding protein transducin $(\mathbf{G} \tau)$; PDE-VII is strictly cAMP-PDE which is insensitive to all now known PDE inhibitors; cognate mRNA was found in lymphocytes, in skeletal muscle, myocardium and the kidney. vated fetal calf serum (FCS), $15 \mathrm{mM}$ Hepes, $1 \mathrm{mM}$ Na pyruvate, $0.1 \mathrm{mM}$ non-essential amino acids, $2 \mathrm{mM}$ L-glutamamine, $50 \mathrm{IU} / \mathrm{ml}$ penicillin, $50 \mu \mathrm{g} / \mathrm{ml}$ streptomycin, and $1 \% \mathrm{ITS}+$ (insulin, transferrin, selenium, and bovine serum albumin).

Measurement of $\left[{ }^{3} \mathrm{H}\right]$ thymidine incorporation. Rat MC were plated into 24-well culture dishes at $5 \times 10^{4}$ cells/well and grown $24 \mathrm{~h}$ to confluency (36). Cells were rendered quiescent by incubating them in Waymouth's medium supplemented with $0.5 \%$ FCS for $72 \mathrm{~h}$ (35). After addition of test compounds and growth factors $1 \mathrm{~h}$ later, cultures were incubated for $16 \mathrm{~h}$. In experiments with $\mathrm{H}-89$, an inhibitor of PKA, the cells were first incubated with or without $\mathrm{H}-89$ for $60 \mathrm{~min}$ then cilostamide was added and incubation continued for $17 \mathrm{~h}$ and concluded as in other experiments. Then $\left[6-{ }^{3} \mathrm{H}\right]$ thymidine, $1 \mu \mathrm{Ci} / \mathrm{ml}$, was added and cultures incubated for an additional $4 \mathrm{~h}(28,29)$. Cells were washed two times with PBS and lysed by addition of $0.2 \mathrm{~N} \mathrm{NaOH}$. After 20 min, the cell lysate was neutralized with $\mathrm{HCl}$, TCA was added to a final concentration of $10 \%$, the solution was passed over glass fiber discs (GF/C, Whatman), washed twice with $10 \%$ TCA, and once with $70 \%$ ethanol. Radioactivity retained on the discs was determined by liquid scintillation counting. Incorporation of $\left[{ }^{3} \mathrm{H}\right]$ thymidine was used as a measure of the rate of mitogenic synthesis of DNA (35). In control experiments, neither $10 \mu \mathrm{M}$ cilostamide nor $10 \mu \mathrm{M}$ rolipram nor both inhibitors combined, influenced significantly the initial $(60 \mathrm{~s})$ uptake of $\left[{ }^{3} \mathrm{H}\right]$ thymidine by MC.

Assay for cAMP. The MC were incubated with test agents in $24-$ well plates for $60 \mathrm{~min}$ (see Fig. 3), or for $16 \mathrm{~h}$ as in the $\left[{ }^{3} \mathrm{H}\right]$ thymidine incorporation experiments. The incubation was terminated by adding 5\% TCA (final concentrations) to the wells, cells scraped, and the mixture was incubated on ice for $0.5 \mathrm{~h}$. The TCA was extracted with water-saturated ether and the cAMP content was measured using radioimmunoassay (RIA) as previously described $(22,23)$.

Lactate dehydrogenase activity $(L D H)$. Activity was assayed in a media of cultured MC at the end of incubation period by measuring the rate of reduction of pyruvate to lactate using Sigma Diagnostics kit (procedure No 228-UV). LDH activity was then calculated from the change in 340-nm absorbance per $1 \mathrm{~min}$ and expressed per unit volume of medium.

Preparation of extracts and fractions of MC for PDE determinations. MC were grown to confluency in $75-\mathrm{cm}^{2}$ tissue culture flasks. Cells were scraped and homogenized in an ice-cold medium containing (final concentrations); $5 \mathrm{mM} \mathrm{MgCl} 2,1 \mathrm{mM}$ EDTA, 1 mM EGTA, 5 $\mathrm{mM} \beta$-mercaptoethanol, $0.1 \mu \mathrm{M}$ leupeptin, $0.1 \mu \mathrm{M}$ pepstatin, and 0.1 $\mu \mathrm{M}$ phenylmethylsulphonyl fluoride, $0.1 \%$ Triton $\mathrm{X}-100$ and $20 \mathrm{mM}$ Tris- $\mathrm{HCl}$ adjusted to $\mathrm{pH}$ 7.4. Cells were homogenized by 10 strokes in a Potter-type teflon-glass homogenizer. The homogenate was centrifuged for $60 \mathrm{~min}$ at $10^{5} \mathrm{~g}$. The supernatant, denoted "extract," was used for PDE assay (23). In experiments when cytosol and total membrane fractions were separated, cells were homogenized similarly, except that $0.3 \mathrm{M}$ sucrose was added and $0.1 \%$ Triton-X-100 was omitted from the homogenization medium. The homogenates were centrifuged at $60 \mathrm{~min}$ at $10^{5} \mathrm{~g}$ and the pellet was resuspended in the same medium, centrifugation repeated; first and second supernatants were combined and constituted the total soluble fraction or "cytosol." The washed second pellet was resuspended again in a medium of the same composition but with $0.1 \%$ Triton X-100 and without sucrose, centrifuged for $40 \mathrm{~min}$ at $10^{5}$ $g$, and the supernatant referred to as "total membrane fraction." The samples were assayed immediately or stored after addition of ethyleneglycol (final concentration $30 \%$ ) at $-20^{\circ} \mathrm{C}$ until used (maximum 6 d). The protein was determined by the Bradford method (24).

Phosphodiesterase (PDE) assay. The PDE activity was measured by incubating the extracts or fractions in a final volume $110 \mu \mathrm{l}$ of the following medium: (final concentrations): $10 \mathrm{mM} \mathrm{MgSO} 4,2 \mathrm{mM}$

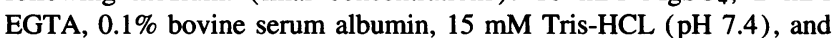
either $0.5 \mu \mathrm{M}\left[{ }^{3} \mathrm{H}\right]$-cAMP or $\left[{ }^{3} \mathrm{H}\right]$-cGMP as substrate $(26,30)$. In experiments examining the activity of $\mathrm{Ca}^{2+}$-calmodulin-dependent PDEs, the reaction mixture also contained $2.01 \mathrm{mM} \mathrm{CaCl}_{2}$, to obtain $10 \mu \mathrm{M} \mathrm{Ca}^{2+}$, and $10 \mu \mathrm{g} / \mathrm{ml}$ of calmodulin (CaM). The PDE activity 
in aliquots incubated without $\mathrm{Ca}^{2+}$ and $\mathrm{CaM}$ (but with $2 \mathrm{mM}$ EGTA, vide supra) was determined as a basal activity $(26,30)$. PDE-III and PDE-IV activities were determined as CAMP-PDE inhibitable by $3 \mu \mathrm{M}$ cilostamide or rolipram, respectively, as in our preceding studies (22, $23)$. At these concentrations $(3 \mu \mathrm{M})$ both rolipram and cilostamide cause maximal inhibition of corresponding PDEs $(22,23)$; no or only slight increase of inhibition was achieved by increasing the dose of rolipram or cilostamide from 3 to $10 \mu \mathrm{M}$. The PDE-II activity was determined as the difference in CAMP-PDE without or with added 5 $\mu \mathrm{M}$ cGMP (22). Stock solutions of all inhibitors were made in $100 \%$ DMSO and all the incubation media, including controls, contained final concentration, $0.1 \%$ DMSO. Hydrolysis of CAMP or cGMP was $<20 \%$ of the substrate and was linearly proportional to incubation time and enzyme protein $(22,23)$.

Measurement of cAMP-dependent protein kinase (PKA) activity in situ. We used a method described by Corbin et al. (25) as in our previous study (22) with minor modifications. Quiescent MC cultures in (diameter $6 \mathrm{~cm}$ ) Petri dishes were incubated either without added agents (controls), or with PDE isozyme inhibitors for $60 \mathrm{~min}$ to assure penetration of compounds into cells, or with forskolin for $10 \mathrm{~min}$. The incubation was terminated by chilling the plate to $0-4^{\circ} \mathrm{C}$ and quickly scraping the cells which were then pelleted by centrifugation at 2,500 $g$ for $5 \mathrm{~min}$ at $0-4^{\circ} \mathrm{C}$. The supernatant was discarded and the packed MC were homogenized in a medium containing (final concentrations): $0.25 \mathrm{M}$ sucrose, $0.5 \mathrm{mM}$ 3-isobutyl, 1-methylxanthine, $4 \mathrm{mM}$ EDTA, and $20 \mathrm{mM}$ MES-NaOH, pH 6.8. The homogenate was centrifuged at $27,000 \mathrm{~g}$ for $30 \mathrm{~min}$ at $0-4^{\circ} \mathrm{C}$. The PKA activity was measured in the supernatant by the incorporation of ${ }^{32} \mathrm{P}-\gamma$-ATP into the oligopeptide Kemptide $(25,26)$. The MC extract was incubated in a mixture (final concentrations ): $10 \mu \mathrm{M}{ }^{32} \mathrm{P}-\gamma$-ATP $(1 \mu \mathrm{Ci}), 0.4 \mathrm{mM}$ EGTA, $0.1 \mathrm{mM}$ EDTA, $8 \mathrm{mM} \mathrm{NaF}, 0.6 \mathrm{mg} / \mathrm{ml}$ BSA, $160 \mu \mathrm{M}$ "Kemptide" $20 \mathrm{mM}$ MES-NaOH, ( $\mathrm{pH} 6.8$ ) either with or without $1 \mu \mathrm{M}$ added cAMP, and $2 \mu \mathrm{g}$ of protein extract per tube. The incubation was carried out for 6 $\min$ at $30^{\circ} \mathrm{C}$, and stopped by placing the incubation mixture on $2 \times 2$ $\mathrm{cm}^{2}$ phosphocellulose papers (Whatman $\mathrm{P} 81$ ) which were then immersed into $10 \mathrm{mM} \mathrm{Na} \mathrm{P}_{2} \mathrm{O}_{7}$ in $1 \% \mathrm{H}_{3} \mathrm{PO}_{4}$. The papers were then washed $(3 \times 15 \mathrm{~min})$ in $1 \% \mathrm{H}_{3} \mathrm{PO}_{4}$ dried and ${ }^{32} \mathrm{P}$ was determined by liquid scintillation counting. Used PDE isozyme inhibitors did not interfere with PKA assay (22). The PKA activity was assayed in one aliquot without cAMP, another aliquot with $1 \mu \mathrm{M}$ cAMP (maximum stimulatory dose), and also in aliquot with $1 \mu \mathrm{M}$ cAMP plus maximum inhibitory dose $(10 \mu \mathrm{M})$ of a specific PKA oligopeptide inhibitor WIPTIDE $(22,26)$. The difference between PKA activity without and with 10 $\mu \mathrm{M}$ WIPTIDE was taken as specific PKA activity, the residual protein kinase activity in the presence of WIPTIDE was subtracted (22). In situ activity of PKA was determined as a ratio of PKA activity measured without added cAMP (-cAMP) to total PKA activity measured with $1 \mu \mathrm{M}$ cAMP (+cAMP) and expressed as (-cAMP/+cAMP) PKA activity ratio $(22,25)$.

MAPK activity. MC grown in 6-cm-diameter dishes were rendered quiescent in $0.5 \%$ FCS, cells were incubated in the same medium containing PDE isozyme inhibitors for $60 \mathrm{~min}$ to assure their penetration into cells or with EGF $10 \mathrm{ng} / \mathrm{ml}$ for $10 \mathrm{~min}$. The incubation was terminated by scraping the cells in $0.2 \mathrm{ml}$ of the lysing buffer (27) (final concentrations): $25 \mathrm{mM}$ Tris-HCL ( $\mathrm{pH} 7.4) 25 \mathrm{mM} \mathrm{NaCl}, 80 \mathrm{mM} \beta$ glycerophosphate, $1 \mathrm{mM} \mathrm{Na} \mathrm{Na} \mathrm{P}_{2} \mathrm{O}_{7}, 1 \mathrm{mM}$ Na pyrophosphate, 10 $\mathrm{mM} \mathrm{MgCl} 2,10 \mathrm{mM} \mathrm{NaF}, 1 \mathrm{mM}$ EGTA, $1 \mathrm{mM}$ PMSF, and $10 \mu \mathrm{g} / \mathrm{ml}$ leupeptin. The scraped cells were sonicated for $10 \mathrm{sec}$ and then centrifuged for $30 \mathrm{~min}$ at $15,000 \mathrm{~g}$. The MAPK activity assay was performed as described (28) with minor modifications. The extract was assayed in a buffer (final concentrations): $25 \mathrm{mM}$ Tris-HCL ( $\mathrm{pH}$ 7.4), $10 \mathrm{mM}$ of $\mathrm{MgCl}_{2}, 1 \mathrm{mM}$ dithiothreitol, $1 \mathrm{mM}$ EGTA, $10 \mu \mathrm{M}$ of PKA inhibitor WIPTIDE, $50 \mathrm{mM}$ ATP, $2 \mu \mathrm{Ci}$ of [ $\left.{ }^{32} \mathrm{P}\right]-\gamma-\mathrm{ATP}$ and $20 \mathrm{ng}$ of myelin basic protein (MBP); the mixture (total volume $50 \mu \mathrm{l}$ ) contained 10 $20 \mu \mathrm{g}$ protein extract from MC. The incubation was carried out at $25^{\circ} \mathrm{C}$ for $15 \mathrm{~min}$ and reaction was stopped by addition of "dissociating buffer" (final concentration): $62.5 \mathrm{mM}$ Tris- $\mathrm{HCl}, \mathrm{pH} 6.8 ; 1 \% \mathrm{SDS}$,
$10 \%$ glycerol, $37.5 \mathrm{mM} \beta$-mercaptoethanol, and $0.05 \%$ bromphenol blue) and boiling for $3 \mathrm{~min}$ at $95-100^{\circ} \mathrm{C}$. The phosphorylated MBP was separated by SDS-PAGE on a $12 \%$ gel. The extent of MBP phosphorylation was determined by autoradiography; autoradiograms were evaluated using dual-wavelength flying-spot scanner (Schimadzu densitometer CS 90000). The effects of EGF or PDE isozyme inhibitors upon MAPK were evaluated as a relative difference of surface area of peaks from basal value (see Fig. 4). Neither cilostamide nor rolipram added to the assay mixture interfered with MAPK activity. In control experiments we determined that overnight incubation of MC with solvent or with drugs or other bioactive agents did not change the appearance of the cells; cells were viable as assessed by trypan blue exclusion. Likewise, at none of the experimental conditions was there was a leak of LDH into the medium. In control experiments we determined total protein content of cells in wells. Protein content was very similar from well to well (average $50 \mu \mathrm{g}$ per well) and therefore results of both $\left[{ }^{3} \mathrm{H}\right]$ thymidine incorporation or CAMP content are expressed as counts per sample.

Statistical evaluation of the results. Statistical analysis was performed by two-tailed $t$ test (for group comparison) or by paired $t$ test as appropriate; relative $(\Delta \%)$ differences were evaluated by paired $t$ test. The values of $P<0.05$ were considered statistically significant.

Materials. Cilostamide, $N$-cyclohexyl- $N$-methyl-4(1,2-dihydro-2oxo-6-quinolyloxy)butyramide (OPC-3639) and cilostazol, 6-[4-1cyclohexyl-1H-tetrazol-5-yl) butoxy]-3,4-dihydro-2(1H)-quinolinone (OPC-13013) were a gift of Otsuka Pharmaceutical Company (Osaka, Japan). Lixazinone, $N$-cyclohexyl- $N$-methyl-4 (7-oxy-1,2,3,5-tetrahydroimide 20 [2,1-b] quinazolin-2-one) butyramide (RS-82856) was a gift from Dr. R. Alvarez (Syntex Research, Palo Alto, CA). The three specific PDE-III inhibitors differed in inhibitory potency towards CAMP-PDE in MC extract: cilostamide (I.D. $50 \cong 4 \times 10^{-8} \mathrm{M}$ ), lixazinone (I.D. $50 \cong 3 \times 10^{-9} \mathrm{M}$ ) and cilostazol (I.D. $50 \cong 2 \times 10^{-7} \mathrm{M}$ ), however, all three antagonists showed similar maximum inhibition at high concentrations. Rolipram, 4-(3-cyclopentyloxy-4-methylphenyl)2-pyrolidine (ZK 62711) was a gift of Berlex Laboratories (Cedar Knolls, NJ). Denbufylline, BRL30892, (1,3-di-n-butyl-7-(2'-oxopropyl)-xanthine was donated by Smith Kline Beecham Pharmaceutical (Worthing, West Sussex, UK). Zardaverine, 6-(4-difluoromethoxy-3methoxyphenyl)-3[2H]-pyridazinone was a gift of Byk-Gulden Lomberg Chemische Fabrik GmbH (Konstanz, Germany). Forskolin, bovine brain calmodulin, ATP, myelin basic protein, Sigma Diagnostics Lactate Dehydrogenase (LD-L) kits were purchased from Sigma Chemical Co. (St. Louis, MO). 8-methoxymethyl-3-isobutyl-1-methylxanthine (8MeoM-IBMX) was a gift of Dr. Jack N. Wells (Vanderbilt University, Nashville, TN). The QAE-Sephadex A-25 resin was purchased from Pharmacia, LKB Inc. (Piscataway, NJ). The cAMP-RIA kits were purchased from Biomedical Technologies Inc. (Stoughton, MA). $\left[8{ }^{3} \mathrm{H}\right]-$ cGMP, ammonium salt, 10 to $30 \mathrm{Ci} / \mathrm{mmol},\left[2,8-{ }^{3} \mathrm{H}\right]$-cAMP, ammonium salt, NEN (NEX 275) $30-50 \mathrm{Ci} / \mathrm{mmol},{ }^{32} \mathrm{P}-\gamma-\mathrm{ATP}$, and $\left[6-{ }^{3} \mathrm{H}\right]-$ thymidine, $5 \mathrm{mCi} / \mu \mathrm{mol}$ were purchased from Amersham Co. (Arlington Heights, IL); PKA inhibitor WIPTIDE and PKA substrate Kemptide were purchased from Peninsula Laboratories Inc. (Belmont, CA). EGF (human, recombinant) was purchased from Collaborative Biomedical Products (Bedford, MA), recombinant human Platelet Derived Growth Factor BB (rHu PDGF-BB) was from Intergen Company (Purchase, NY). Weymouth's culture medium was from GIBCO BRL (Gaithersburg, MD). Tissue culture plates were purchased from Costar Corp. (Cambridge, MA). Tissue culture medium, heat-inactivated fetal bovine calf serum, Hepes, $\mathrm{Na}$ pyruvate, and non-essential amino acids were from GIBCO BRL. Glutamine, penicillin, and streptomycin were from Cellgro (Washington, DC). ITS + was obtained from Collaborative Giomedical Products (Bedford, MA). Glass fiber discs (GF/C) were from Whatman Inc. (Clifton, NJ). Other reagents, all of highest purity grades, were purchased from standard suppliers. $\left[{ }^{3} \mathrm{H}\right]$-cAMP and $\left[{ }^{3} \mathrm{H}\right]$-cGMP were, prior to use as substrates in CAMP-PDE or cGMP-PDE assay, purified according to a method of Kincaid and Manganiello (29). 

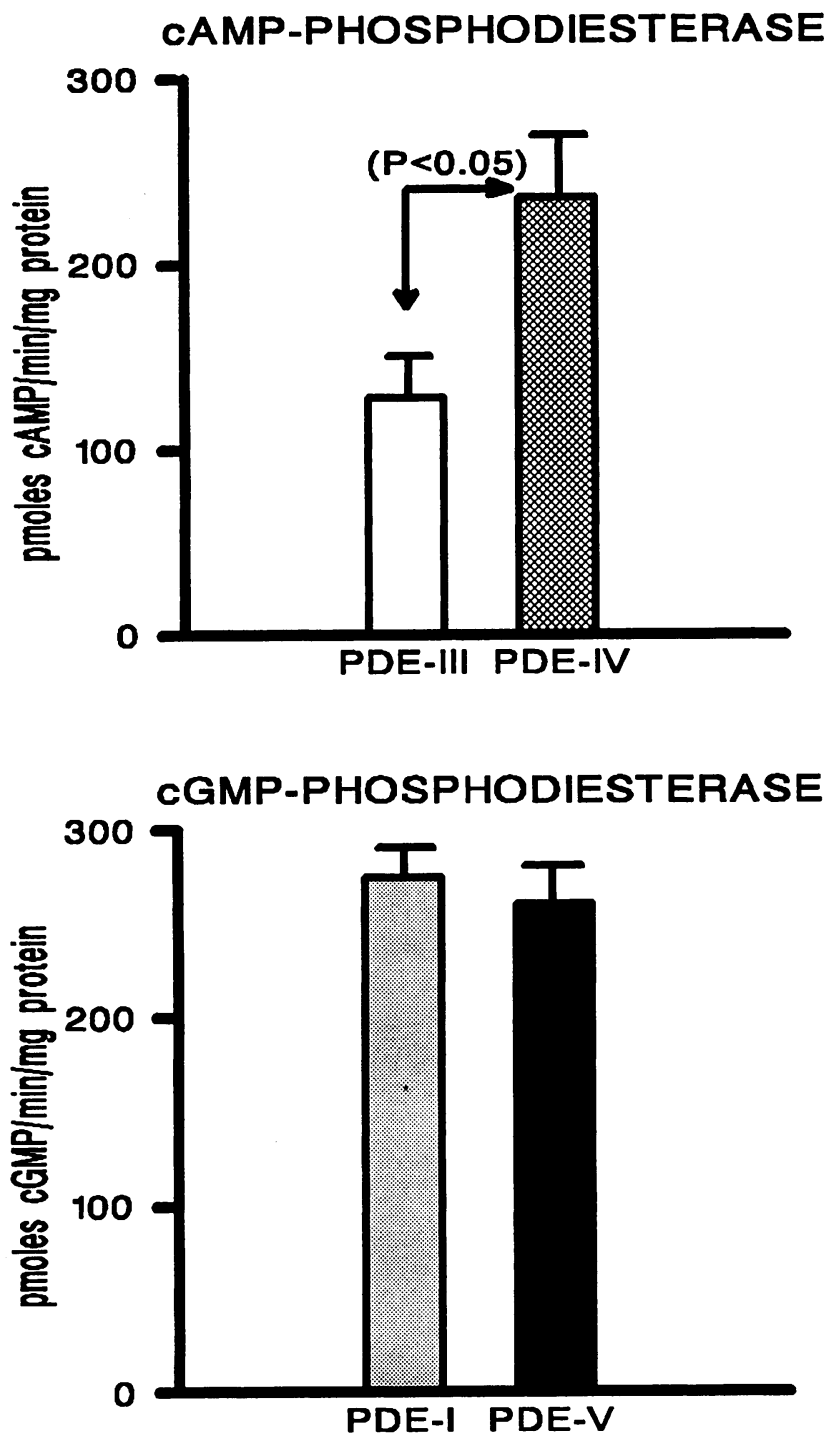

Figure 1. PDE isozymes in extract from rat MC. Extracts of rat MC were prepared, assayed and activities of PDE isozymes are as defined, by sensitivity to selective inhibitors or dependence on modulating agents (for details, see Methods). Each bar denotes $n=4-5$ experiments. (Upper panel) cAMP-PDE activities ( $\square$ ) PDE-III and (圆) PDE-IV. The rolipram-sensitive PDE-IV activity was significantly higher than PDE-III $(P<0.05$, paired $t$ test). (Lower panel) cGMP-PDE activities $(\square)$ and $(\square)$ PDE-V.

\section{Results}

$P D E$ activities in $M C$. The activities of CAMP-PDE and cGMPPDE were assayed in extract of MC prepared as described in Methods. The total cAMP-PDE activity $(381 \pm 89$ pmoles cAMP/min per mg protein; $n=5$ ) was virtually the same as total cGMP-PDE activity ( $385 \pm 42$ pmoles cGMP/min per $\mathrm{mg}$ protein, $n=4$ ). The presence of five major families (types) of PDE isozymes in MC was surveyed using characteristic responses to PDE isozyme-selective synthetic inhibitors $(24,25)$ and/or biologic modulators (21-23). The two types of cAMPPDE activities detected in extracts from MC were the rolipramsensitive PDE-IV and, about two times lower, activity of PDEIII (Fig. 1, upper panel). No cGMP-stimulated PDE-II or $\mathrm{Ca}^{2+}$ /
CaM-dependent cAMP-PDE, i.e., PDE-I activity hydrolyzing cAMP, was detected in MC. The failure to detect PDE-I which hydrolyzes CAMP was not due to the lack of sensitivity of the PDE assay. As a control, in the same experiments $\mathrm{Ca}^{2+} / \mathrm{CaM}$ markedly stimulated ( $\Delta \%=+95)$ cAMP-PDE in cytosol from cultured rat inner medullary duct cells (23). Addition of $5 \mu \mathrm{M}$ cGMP resulted in inhibition $(-\Delta \% 20 \pm 4 ; n=3, P<0.05$, paired $t$ test) of cAMP-PDE, reflecting the presence of PDEIII and absence of any substantial activity of PDE-II. Unlike in extract from whole glomeruli (22) or $\mathrm{LLCPK}_{1}$ cells (30) under none of the assay conditions added $5 \mu \mathrm{M}$ cGMP increased cAMP hydrolysis. The arithmetic sum (22) of the rolipraminhibitable cAMP-PDE (PDE-IV) and the cilostamide-inhibitable cAMP-PDE activity (PDE-III) in extract from MC was not significantly different from total cAMP-PDE measured in the presence of $\mathrm{Ca}^{2+} / \mathrm{CaM}$ in the same experiment (results not shown). These observations thus indicate that in rat MC the cAMP is metabolized exclusively by two PDE isozymes: by PDE-IV and to a lesser degree $(\sim 33 \%)$ by PDE-III. With respect of cGMP-PDE, MC contain about the same activity of PDE-I which hydrolyzes cGMP and the activity of PDE-V independent of $\mathrm{Ca}^{2+} / \mathrm{CaM}$ (Fig. 1, lower panel). The determination of cAMP-PDE separately in the cytosol and in total membrane fraction (see Methods) showed that majority of both PDE-III and PDE-IV activities $(\sim 75 \%)$ were contained in cytosolic fraction (data not shown).

Both rolipram and cilostamide showed near maximum inhibitory effect of cAMP-PDE at $3 \mu \mathrm{M}$ and only slightly higher at $10 \mu \mathrm{M}$. Zardaverine, the "hybrid III/IV inhibitor," reported to antagonize both isozymes PDE-III and PDE-IV (31), inhibited potently cAMP-PDE in MC extract; the extent of inhibition of cAMP-PDE in extract from MC by $3 \mu \mathrm{M}$ zardaverine ( $\Delta \%$ $-71 \pm 1$; mean \pm SEM, $n=3$ ) was similar to arithmetic sum of cAMP-PDE inhibition by $3 \mu \mathrm{M}$ cilostamide $(\Delta \%-32 \pm 5$; mean \pm SEM, $n=5)$ and by $3 \mu \mathrm{M}$ rolipram $(\Delta \%-52 \pm 3$; mean \pm SEM; $n=5)$, added together $(\Delta \%-80 \pm 3 \%$; mean \pm SEM; $n=3$ ).

Effect of EGF and PDGF upon $\left[{ }^{3} \mathrm{H}\right]$ thymidine incorporation into DNA of $M C$. Incubation with EGF resulted in a dosedependent $\left(10^{-12}-10^{-6} \mathrm{M}\right.$ EGF) stimulation of mitogenesis in $\mathrm{MC}$, as determined by $\left[{ }^{3} \mathrm{H}\right]$ thymidine incorporation assay, with maximum reached at $3-30 \mathrm{ng} / \mathrm{ml}$ EGF and the $1 / 2$ maximum stimulation was at $0.2 \mathrm{ng} / \mathrm{ml}$ EGF. In all subsequent experiments $10 \mathrm{ng} / \mathrm{ml}$ EGF was employed as a stimulatory dose; $10 \mathrm{ng} / \mathrm{ml}$ EGF enhanced $\left[{ }^{3} \mathrm{H}\right]$ thymidine incorporation fivefold ( $\Delta \% 541 \pm 34 ; P<0.01$; paired $t$ test $n=12$ ). PDGF also stimulated $\left[{ }^{3} \mathrm{H}\right]$ thymidine incorporation in a dose-dependent way, the maximum 10-fold stimulation was reached at 10-30 $\mathrm{ng} / \mathrm{ml}$.PDGF.

Effect of cAMP agonists and PDE isozyme inhibitors upon $\left[{ }^{3} \mathrm{H}\right]$ thymidine incorporation in $\mathrm{MC}$. Effects of cAMP metabolism-influencing or cAMP-mimicking agents upon mitogenesis were determined by $\left[{ }^{3} \mathrm{H}\right]$ thymidine incorporation in the ambient state, when cells were only under autocrine/paracrine influence of self-produced mitogens (1-4), as well as after exposure to added EGF or PDGF.

The MC were incubated either with $10 \mu \mathrm{M}$ forskolin or with $1 \mathrm{mM}$ dibutyryl cAMP ( $\mathrm{B}_{2} \mathrm{CAMP}$ ) without addition of PDE inhibitors (Fig. 2, $A$ and $B$ ), or with cAMP-PDE isozyme inhibitors, but without stimulants of adenylate cyclase (Fig. 2, $C$ and $D$ ). Both $\mathrm{B}_{2}$ cAMP and forskolin, which increased cAMP 

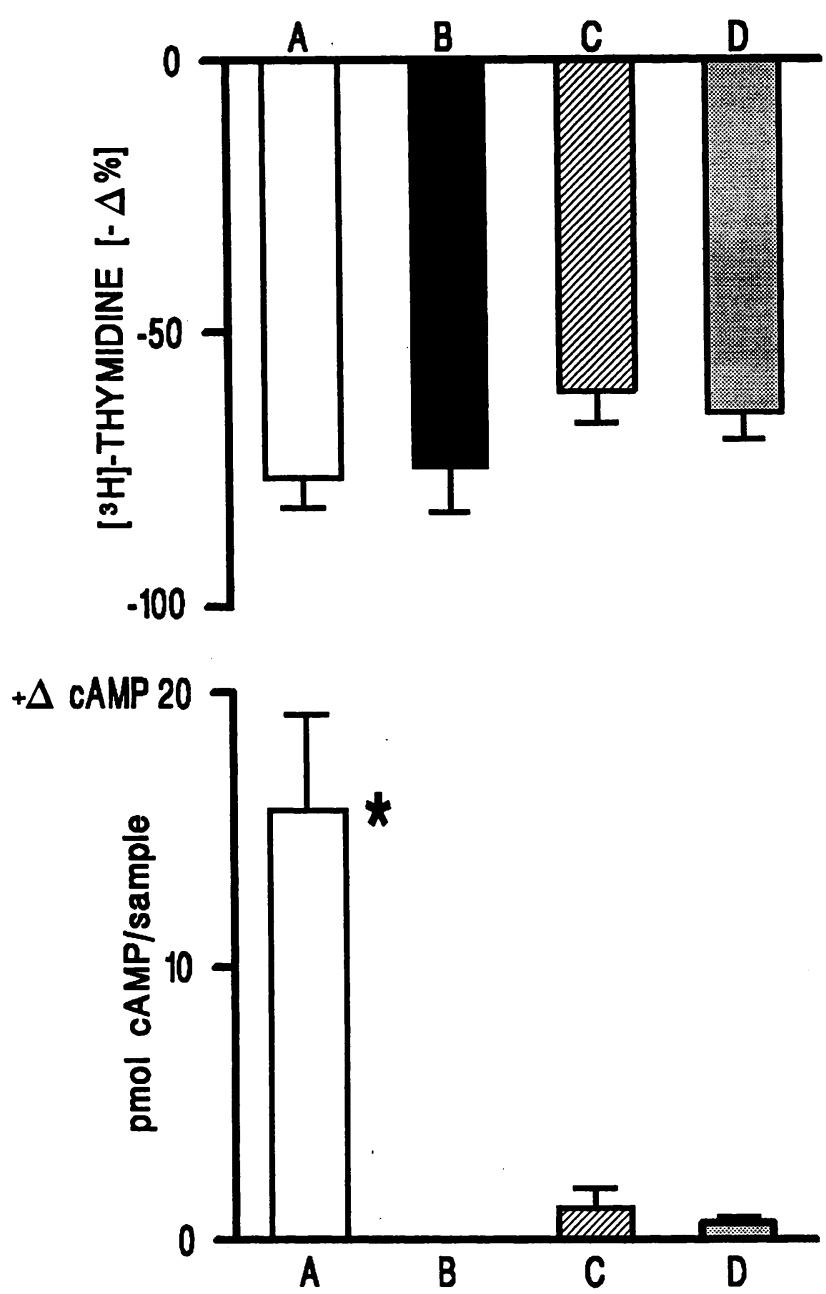

Figure 2. Effect dibutyryl cAMP (DBcAMP) and cAMP-influencing agents upon $\mathrm{MC}$ under ambient state $\left[{ }^{3} \mathrm{H}\right]$ thymidine incorporation (upper panel) and cAMP content (lower panel). (Upper panel) Average incorporation of $\left[{ }^{3} \mathrm{H}\right]$ thymidine was $15,048 \pm 1,609 \mathrm{dpm}$ after a 4 -h incubation. The bars denote relative changes $(-\Delta \%)$ in $\left[{ }^{3} \mathrm{H}\right]$ thymidine incorporation (upper panel) and in $(+\Delta \%)$ of cAMP content (lower panel) in the presence of $(A) 10 \mu \mathrm{M}$ forskolin, (B) $1 \mathrm{mM} \mathrm{DBcAMP \text {, }}$ (C) $10 \mu \mathrm{M}$ cilostamide, and (D) $10 \mu \mathrm{M}$ zardaverine. Each bar denotes mean \pm SEM of $n=4-7$ experiments. Inhibition of $\left[{ }^{3} \mathrm{H}\right]$ thymidine incorporation was significant under all conditions $(A-D)$. The extent of inhibition $(-\Delta \%)$ was not significantly $(t$ test $)$ different between the four conditions (A-D). (Lower panel) Increase of cAMP content (in pmoles cAMP per well) under the same conditions $(A, C$, and $D)$ as in the upper panel. With DBcAMP (condition B) cAMP was not assayed. Asterisk $(*)$ denotes significant $(t$ test $)$ increase in cAMP content. Incubation with cilostamide $(C)$ or zardaverine $(D)$ caused no significant increase of cAMP content.

levels in MC more than 10-fold, caused profound inhibition of $\left[{ }^{3} \mathrm{H}\right]$ thymidine incorporation (Fig. 2). The two cAMP-PDE isozyme-specific inhibitors $10 \mu \mathrm{M}$ cilostamide (PDE-III) and $10 \mu \mathrm{M}$ zardaverine (PDE-III/IV) inhibited $\left[{ }^{3} \mathrm{H}\right]$ thymidine incorporation to a similar degree as forskolin and DBcAMP but, in a contrast to forskolin, without significant increase in cAMP content (Fig. 2, $A, C$, and $D$ ). Incubation of MC with $10 \mu \mathrm{M}$ rolipram, antagonist of PDE-IV which is abundant in MC (Fig.
1) rather modestly inhibited ( $\Delta \%-20 \pm 7$, mean \pm SEM; $n=4$, $P<0.05)\left[{ }^{3} \mathrm{H}\right]$ thymidine incorporation. Also $3 \mu \mathrm{M}$ cilostamide caused about 3-fold greater inhibition of mitogenesis than $3 \mu \mathrm{M}$ rolipram (Tables I and II), inspite that PDE-IV activity in MC is about twofold higher than PDE-III (Fig. 1, upper panel). Zardaverine at $10 \mu \mathrm{M}$ was equipotent to $10 \mu \mathrm{M}$ cilostamide (Fig. 2, $C$ and $D$ ) but at $3 \mu \mathrm{M}$ had a lesser effect (Table I). Neither $10 \mu \mathrm{M}$ 8-MeoM-IBMX, selective inhibitor of PDE-I $(23,32)$, nor zaprinast $(10 \mu \mathrm{M})$, an antagonist of PDE-V (20, 23 ), inhibited $\left[{ }^{3} \mathrm{H}\right]$ thymidine incorporation, either under ambient conditions or when stimulated with EGF (data not shown).

Structurally unrelated antagonists of PDE-III and PDE-IV also showed differential inhibitory effect upon $\left[{ }^{3} \mathrm{H}\right]$ thymidine incorporation as did cilostamide and rolipram. Antagonist of PDE-III $(10 \mu \mathrm{M})$ cilostazol and PDE-IV antagonist $(3 \mu \mathrm{M})$ denbufyllin inhibited cAMP-PDE to the same degree $(-39 \% \pm 7, n=7)$. Yet $10 \mu \mathrm{M}$ cilostazol reduced $\left[{ }^{3} \mathrm{H}\right]-$ thymidine incorporation $(\Delta \%-57 \pm 3$; mean \pm SEM, $n=3)$, fourfold more $(P<0.001 ; t$ test $)$ than did $3 \mu \mathrm{M}$ denbufylline $(\Delta \%-14 \pm 3$; mean \pm SEM; $n=4)$. Also, another structurally different potent PDE-III inhibitor, $1 \mu \mathrm{M}$ lixazinone (33), lowered $\left[{ }^{3} \mathrm{H}\right]$ thymidine incorporation $(\Delta \%-52 \pm 4 \%$, mean \pm SEM; $n=3$ ), i.e., to a similar extent as $3 \mu \mathrm{M}$ cilostamide $(\Delta \%-60 \pm 2$, mean $\pm \mathrm{SEM} ; n=4)$.

A combination of cilostamide and rolipram is additive in blocking mitogenesis (Table II) and this combined effect is especially pronounced at lower concentrations of these compounds. For example, in the ambient state, $0.3 \mu \mathrm{M}$ cilostamide and $0.3 \mu \mathrm{M}$ rolipram combined inhibited $\left[{ }^{3} \mathrm{H}\right]$ thymidine incorporation by $(\Delta-51 \pm 7 \%, n=4)$, i.e., similarly as $10 \mu \mathrm{M}$ cilostamide alone $(\Delta-61 \pm 6 \%, n=7)$. Combination of equimolar cilostamide with rolipram do suppress mitogenesis dosedependently to the same relative (\%) degree both in the ambient and EGF-stimulated states (data not shown). Consequently, the decrease in net rate of $\left[{ }^{3} \mathrm{H}\right]$ thymidine incorporation by inhibitors in EGF-stimulated cells was under all tested conditions manyfold greater than under the ambient conditions (Table II).

The in situ activity of PKA determined as (-cAMP/ + cAMP) PKA activity ratio $(22,25)$, was increased significantly under all tested conditions (Fig. 3, upper panel). No significant change in cAMP accumulation was detected neither with rolipram alone or cilostamide alone (Fig. 3, middle panel). Only minor, albeit statistically significant, increase of cAMP occurred with cilostamide and rolipram combined, whereas forskolin increased cAMP $\sim 20$-fold (center of Fig. 3). After 16 $h$ incubation (when $\left[{ }^{3} \mathrm{H}\right]$ thymidine incorporation was determined) the cAMP levels, under all conditions, were $>3 \times$ higher than after $1 \mathrm{~h}$ incubation, however the relative pattern of levels was identical: neither rolipram nor cilostamide alone caused cAMP increase, rolipram and cilostamide combined caused small but significant increase in cAMP and forskolin increased cAMP $>40 \times$.

Interestingly, incubation with cilostamide increased in situ activity of PKA only slightly ( $\Delta+29 \%)$ but significantly more than rolipram (Fig. 3, upper panel) but inhibited to a far greater extent $(\Delta-191 \%)$ the $\left[{ }^{3} \mathrm{H}\right]$ thymidine incorporation (Fig. 3, lower panel). Although in situ PKA activity was further significantly increased by incubation with rolipram and cilostamide combined, and in situ PKA was completely activated by forskolin, the extent of suppression of $\left[{ }^{3} \mathrm{H}\right]$ thymidine incorporation was not significantly different between $\mathrm{MC}$ incubated under 
Table I. Effect of dibutyrylcAMP (DBcAMP), Forskolin and PDE Isozyme Inhibitors Upon [ $\left.{ }^{3} H\right]$ Thymidine Incorporation and cAMP Levels in MC Incubated in Ambient State and in the Presence of $10 \mathrm{ng} / \mathrm{ml}$ of EGF

\begin{tabular}{|c|c|c|c|c|c|c|c|c|c|c|c|c|}
\hline & \multicolumn{6}{|c|}{ Ambient state } & \multicolumn{6}{|c|}{ EGF stimulated state } \\
\hline & $n^{*}$ & $\begin{array}{c}\Delta \% \\
{\left[{ }^{3} \mathrm{H}\right] \text { thymidine }} \\
\text { incorporation }\end{array}$ & $P$ value ${ }^{\ddagger}$ & $n^{*}$ & $\begin{array}{c}\Delta \text { pmoles } \\
\text { cAMP/mg } \\
\text { protein }\end{array}$ & $P$ value $^{\ddagger}$ & $n^{*}$ & $\begin{array}{c}\Delta \% \\
{\left[{ }^{3} \mathrm{H}\right] \text { thymidine }} \\
\text { incorporation }\end{array}$ & $P$ value ${ }^{\ddagger}$ & $n^{*}$ & $\begin{array}{c}\Delta \text { cAMP } \\
\text { pmoles } / \mathrm{mg} \\
\text { protein }\end{array}$ & $P$ value $^{\ddagger}$ \\
\hline Dibutyryl cAMP (1 mM) & (4) & $-75 \pm 8 \%$ & $<0.005$ & & N.D. & & (4) & $-83 \pm 7 \%$ & $<0.001$ & & N.D. & \\
\hline Forskolin $(10 \mu \mathrm{M})$ & (6) & $-78 \pm 5 \%$ & $<0.001$ & (6) & $+297 \pm 44$ & $<0.005$ & (6) & $-90 \pm 1 \%$ & $<0.001$ & (4) & $+385 \pm 47$ & $<0.005$ \\
\hline Cilostamide $(3 \mu \mathrm{M})$ & (6) & $-67 \pm 3 \%$ & $<0.001$ & (7) & $+5 \pm 3$ & N.S. & (6) & $-44 \pm 6 \% "$ & $<0.001$ & (7) & $+7 \pm 4$ & N.S. \\
\hline Rolipram (3 $\mu \mathrm{M})$ & (6) & $-20 \pm 5 \%$ & $<0.02$ & (7) & $+9 \pm 5$ & N.S. & (6) & $-24 \pm 6 \%$ & $<0.02$ & (7) & $+8 \pm 3$ & $<0.05$ \\
\hline Zardaverine $(3 \mu \mathrm{M})$ & (5) & $-43 \pm 6 \%{ }^{8}$ & $<0.005$ & (4) & $+15 \pm 7$ & N.S. & (5) & $-22 \pm 7 \%$ & $<0.05$ & (4) & $+8 \pm 10$ & N.S. \\
\hline
\end{tabular}

Relative changes in $\left[{ }^{3} \mathrm{H}\right]$ thymidine incorporation are expressed as $\Delta \%$; under the ambient state the mean incorporation was $22,520 \pm 3,765 \mathrm{dpm} / 4$ $\mathrm{h}$; mean \pm SEM, $(\mathrm{n}=27)$ and with EGF $98,591 \pm 13,174 \mathrm{dpm} / 4 \mathrm{~h}$, mean $\pm \operatorname{SEM}(n=27)$. The average content of cAMP under ambient state was $27 \pm 2$ pmoles $/ \mathrm{mg}$ protein and with EGF was $42 \pm 4$ pmole/mg protein. Effect of agents upon cAMP content is expressed as $\Delta$ change from basal value in pmoles cAMP/mg protein. For further details see Methods. ${ }^{*}$ Number of experiments. ${ }^{\ddagger} P$ value for significance of changes in $\left[{ }^{3} \mathrm{H}\right]$ thymidine incorporation or cAMP content ( $t$ test; $P<0.05$ or higher degree of significance). NS (not signficiant; $P \geq 0.05$ ). ${ }^{\S}$ Significantly $(t$ test; $P<0.05$ or higher degree of significance) lower than values for DBcAMP, forskolin or cilostamide. Effect of cilostamide under ambient conditions was not significantly different from DBcAMP or forskolin. "Value significantly lower than corresponding value in ambient state, and also lower than effect of DBcAMP and forskolin in EGF-stimulated state ( $t$ test; $P<0.05$ or higher degree of significance. 'Significantly $(t$ test; $P<0.05$ or higher degree of significance) lower than value with cilostamide.

these conditions and in the presence of cilostamide alone (Fig. 3). When H-89, a specific inhibitor of PKA (34), was included into incubation medium the suppression of mitogenesis in MC by cilostamide was significantly diminished. In the cells incubated with $3 \mu \mathrm{M}$ cilostamide and $0.5 \mu \mathrm{M} \mathrm{H}-89$ the decrease in $\left[{ }^{3} \mathrm{H}\right]$ thymidine incorporation $(\Delta-25 \pm 8 \%$, mean $\pm \mathrm{SEM} ; n$ $=4)$ was significantly $(P<0.05 ; t$ test $)$ less than with $3 \mu \mathrm{M}$ cilostamide alone $(\Delta-48 \pm 3 \%$, mean \pm SEM; $n=4)$.

Although cilostamide was more than three times more effective at inhibiting mitogenesis (Fig. 3) than rolipram, in situ activation of PKA by cilostamide was only slightly higher than with rolipram (Fig. 3). This comparison rises the possibility that the actions of PDE-III and PDE-IV upon cAMP metabolism in MC may be functionally compartmentalized. Therefore, we compared effects of cilostamide and rolipram upon cAMP accumulation in MC when cAMP synthesis was enhanced by forskolin, a nonspecific stimulator of adenylate cyclase. In the presence of forskolin rolipram enhanced cAMP accumulation by $10-100$-fold (Table III), whereas cilostamide in equimolar concentrations barely affected cAMP content (increase about $\Delta+37 \%)$ and this effect was significant only with $3 \mu \mathrm{M}$ forskolin under ambient conditions (Table III $A$ ). Since cilostamide is a much more potent inhibitor of mitogenesis than rolipram (Tables I and II and Fig. 3) these observations do suggest a special relationship between cAMP pool metabolized by PDE-III and regulation of mitogenesis.

MAPK activity. To discern whether PDE-isozyme antagonists inhibited mitogenesis as proposed (Introduction) the activity of MAPK was determined. In MC incubated with EGF the MAPK activity was about threefold enhanced (Fig. 4). The incubation in the presence of PDE antagonists, cilostamide with rolipram, a treatment which increased cAMP (Fig. 3), stimulated in situ activity of PKA $(\Delta+188 \pm 48 \%)$ and inhibited mitogenesis (Fig. 3, lower panel), resulted in a significant decrease of MAPK activity, both in the ambient state and when stimulated by EGF (Fig. 4). The relative $(-\Delta \%)$ inhibition of

Table II. The Net Changes (Inhibition) of $\left[^{3} H\right]$ Thymidine Incorporation into MC in Response to Antagonists of PDE-III and PDE-IV in Ambient State and When Stimulated by $10 \mathrm{ng} / \mathrm{ml}$ EGF

\begin{tabular}{|c|c|c|c|c|}
\hline \multirow[b]{3}{*}{ Inhibitor } & \multicolumn{4}{|c|}{$\left[{ }^{3} \mathrm{H}\right]$ Thymidine incorporation } \\
\hline & \multicolumn{2}{|c|}{ Ambient state } & \multicolumn{2}{|c|}{ EGF-stimulated state } \\
\hline & $\Delta \%$ & Net difference & $\Delta \%$ & Net difference \\
\hline $3 \mu \mathrm{M}$ cilostamide & $-65 \pm 4 \% *$ & $9.5 \pm 1.6^{\ddagger}$ & $-38 \pm 3 \% * \pi$ & $38.4 \pm 6.2^{\ddagger 8}$ \\
\hline $3 \mu \mathrm{M}$ rolipram & $-24 \pm 2 \% "$ & $3.5 \pm 0.6^{\|}$ & $-27 \pm 6 \%$ & $27.7 \pm 9.1^{8}$ \\
\hline $3 \mu \mathrm{M}$ cilostamide and $3 \mu \mathrm{M}$ rolipram & $-84 \pm 2 \% * *$ & $11.7 \pm 2.0$ & $-74 \pm 5 \% * *$ & $68.0 \pm 14.0^{\S}$ \\
\hline
\end{tabular}

* Relative (\%) decrease of $\left[{ }^{3} \mathrm{H}\right]$ thymidine incorporation. ${ }^{\ddagger}$ Inhibition as net decrease of $\left[{ }^{3} \mathrm{H}\right]$ thymidine incorporation $\left(\mathrm{dpm} \times 10^{3}\right)$ in response to PDE isozyme inhibitors. All values are mean \pm SEM from $n=5$ experiments. ${ }^{\S}$ Values significantly $(t$ test; $P<0.05$ or higher degree of significance $)$ higher than corresponding values in ambient state. "Significantly $(P<0.05$ or higher degree of significance; $t$ test) lower than corresponding value with cilostamide. "Significantly $(P<0.05 ; t$ test $)$ lower than corresponding value in ambient state. ** Significantly $(P<0.05$ or higher degree of significance; $t$ test) higher than corresponding value with cilostamide alone. 


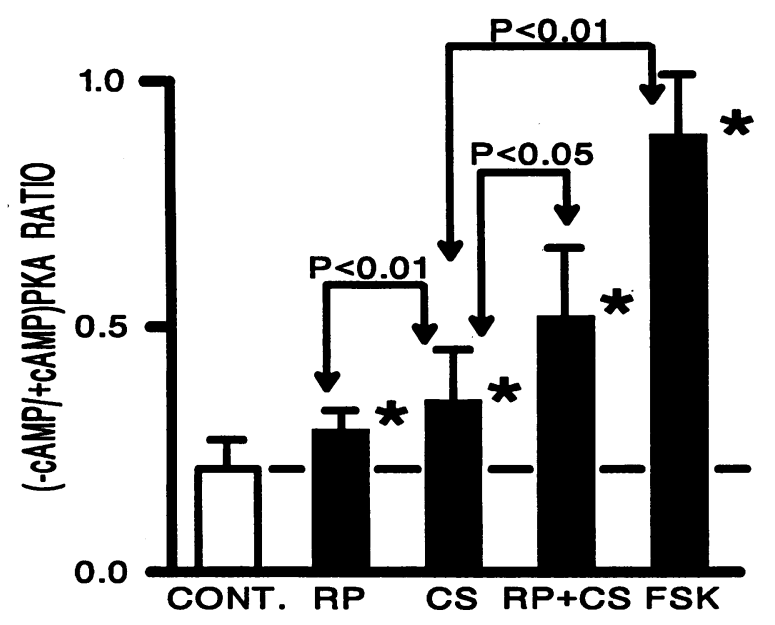

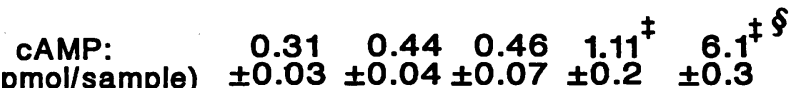

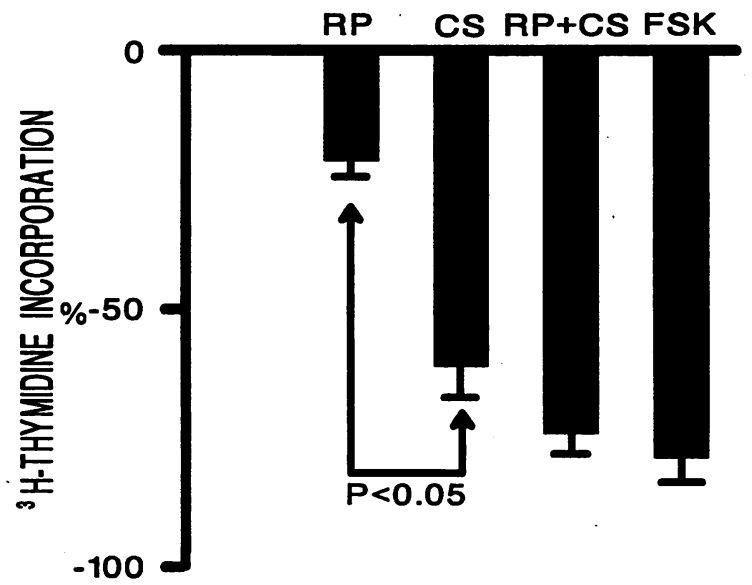

Figure 3. The effect of PDE isozyme antagonists: $10 \mu \mathrm{M}$ cilostamide (CS), $10 \mu \mathrm{M}$ rolipram (RP), or $10 \mu \mathrm{M}$ cilostamide with $10 \mu \mathrm{M}$ rolipram $(R P+C S)$ and of $10 \mu \mathrm{M}$ forskolin $(F S K)$ upon in situ activation of PKA ( upper panel), cAMP accumulation (middle panel) and inhibition $(-\Delta \%)$ of $\left[{ }^{3} \mathrm{H}\right]$ thymidine incorporation (lower panel) in $\mathrm{MC}$ in the ambient state. Differences were evaluated statistically by $t$ test. (Upper panel) Bars denote in situ PKA activity after a 1-h incubation without (control, "Cont."), or with addition of any test agents. Asterisk (*) denotes significant increase in (-cAMP/+cAMP) PKA activity ratio (paired $t$ test, $P<0.05$, or higher degree of significance). Each bar denotes mean \pm SE of $n=4-8$ experiments. The middle panel shows cAMP content in MC incubated for $1 \mathrm{~h}$ without ("Cont.") or with PDE inhibitors or FSK, as denoted above and below the numbers. Each number denotes mean \pm SEM of three experiments run in triplicates. ${ }^{\ddagger}$ Significantly different from controls $(P<0.05, t$ test $)$; ${ }^{8}$ significantly different from all other values $(P<0.01$, test $)$. The lower panel denotes inhibition of mitogenesis $(-\Delta \%)$ in response to test agents. The values for inhibition by CS, CS + RP and FSK were not significantly different from each other and significantly $(P<0.05)$ different from value for RP. Each bar denotes mean \pm SEM from $n=5-11$ experiments.

MAPK by PDE isozyme antagonists was similar in ambient and EGF stimulated states (Fig. 4).

Finally, we explored the effects of PDE isozymes inhibitors upon MC stimulated by another cytokine, PDGF. Incubation with $10 \mu \mathrm{M}$ cilostamide suppressed markedly ( $\Delta \%-69 \pm 11$; $n=3 ; P<0.05)$ mitogenesis in MC stimulated with $10 \mathrm{ng} /$
Table III. Effect of Cilostamide and Rolipram Upon cAMP Accumulation in MC Stimulated by Forskolin (FSK)

\begin{tabular}{lcl}
\hline & Ambient state & With $10 \mathrm{ng} / \mathrm{ml}$ EGF \\
\hline $\begin{array}{l}\text { A. Incubation with } 3 \mu \mathrm{M} \text { FSK } \\
\text { basal (no additions) }\end{array}$ & $0.99 \pm 0.12(6)$ & $1.06 \pm 0.03(6)$ \\
$3 \mu \mathrm{M}$ FSK & $6.57 \pm 0.37(6)$ & $10.5 \pm 0.91^{*}(6)$ \\
$3 \mu \mathrm{M}$ FSK with $3 \mu \mathrm{M}$ & & \\
$\quad$ cilostamide & $11.23 \pm 1.1^{\ddagger}(6)$ & $13.2 \pm 1.0(6)$ \\
$3 \mu \mathrm{M}$ FSK with $3 \mu \mathrm{M}$ & & \\
$\quad$ rolipram & $64.8 \pm 5.92^{\ddagger}(6)$ & $95.3 \pm 8.5^{\ddagger *}(6)$ \\
$\begin{array}{l}\text { B. Incubation with } 10 \mu \mathrm{M} \text { FSK } \\
\text { basal (no additions) }\end{array}$ & $1.31 \pm 0.07(12)$ \\
$\begin{array}{l}10 \mu \mathrm{M} \text { FSK } \\
10 \mu \mathrm{M} \text { FSK with } 10 \mu \mathrm{M}\end{array}$ & $13.1 \pm 0.88(12)$ \\
$\quad$ cilostamide \\
$\begin{array}{l}10 \mu \mathrm{M} \text { FSK with } 10 \mu \mathrm{M} \\
\text { rolipram }\end{array}$ & $15.0 \pm 0.7(12)$ & \\
& $229.1 \pm 24.1^{\ddagger}(11)$ &
\end{tabular}

MC were incubated in wells in a serum-free medium for $18 \mathrm{~h}$ with indicated agents and accumulated cAMP was determined; for details see METHODS. Each value denotes pmoles CAMP/well; mean \pm SEM from $n$ samples (in parentheses). Under all conditions FSK increased cAMP significantly $(P<0.001 ; t$ test) over basal. *Values from cells exposed to EGF significantly ( $t$ test; $P<0.05$ for higher degree of significance) higher than corresponding value under ambient conditions. ‡ denotes values significantly $(t$ test; $P<0.05$ or higher degree of significance) higher than value with FSK alone.

ml PDGF. Combination of $3 \mu \mathrm{M}$ cilostamide and $3 \mu \mathrm{M}$ rolipram also caused pronounced inhibition of $\left[{ }^{3} \mathrm{H}\right]$ thymidine incorporation in MC stimulated by $0.1 \mathrm{ng} / \mathrm{ml}$ PDGF ( $\Delta-72 \pm 3 \%$, mean \pm SEM; $n=3, P<.01$ ) or stimulated by $1 \mathrm{ng} / \mathrm{ml}$ PDGF $(\Delta-67 \pm 4 \%$, mean \pm SEM; $n=3, P<.01)$; forskolin had similar inhibitory effect as in EGF-stimulated MC (data not shown).

\section{Discussion}

Present observation that forskolin and $\mathrm{B}_{2} \mathrm{cAMP}$ inhibit mitogenesis in $\mathrm{MC}$, as assessed by $\left[{ }^{3} \mathrm{H}\right]$ thymidine incorporation $(35,36)$, indicates that in MC the negative "crosstalk" (12) between mitogen-activated protein phosphorylation cascade pathway and the cAMP-PKA pathways does exist $(12,14-17)$. The inhibitory input of the activated cAMP-PKA pathway is very effective since it suppresses $\left[{ }^{3} \mathrm{H}\right]$ thymidine incorporation both in the ambient state (Figs. 2 and 3 ) as well as when MC are under stimulation of potent mitogens EGF or PDGF. MC, more than any other resident cell type populating glomerulus are site of production of growth factors and cytokines $(1-4)$. Therefore, MC when grown in vitro are most likely exposed to autocrine/paracrine effects of endogenously synthetized mitogens. On the other hand, cells incubated with added high doses of EGF or PDGF will presumably approximate the situation of MC in immuno-inflammatory glomerular diseases, when both stimulated glomerular cells produce endogenous mitogens at a higher rate (2-4) and are, in addition, exposed to a large quanta of cytokines produced by neutrophils and other infiltrating inflammatory cells (5).

Guided by our recent findings that cAMP-PKA pathway in 

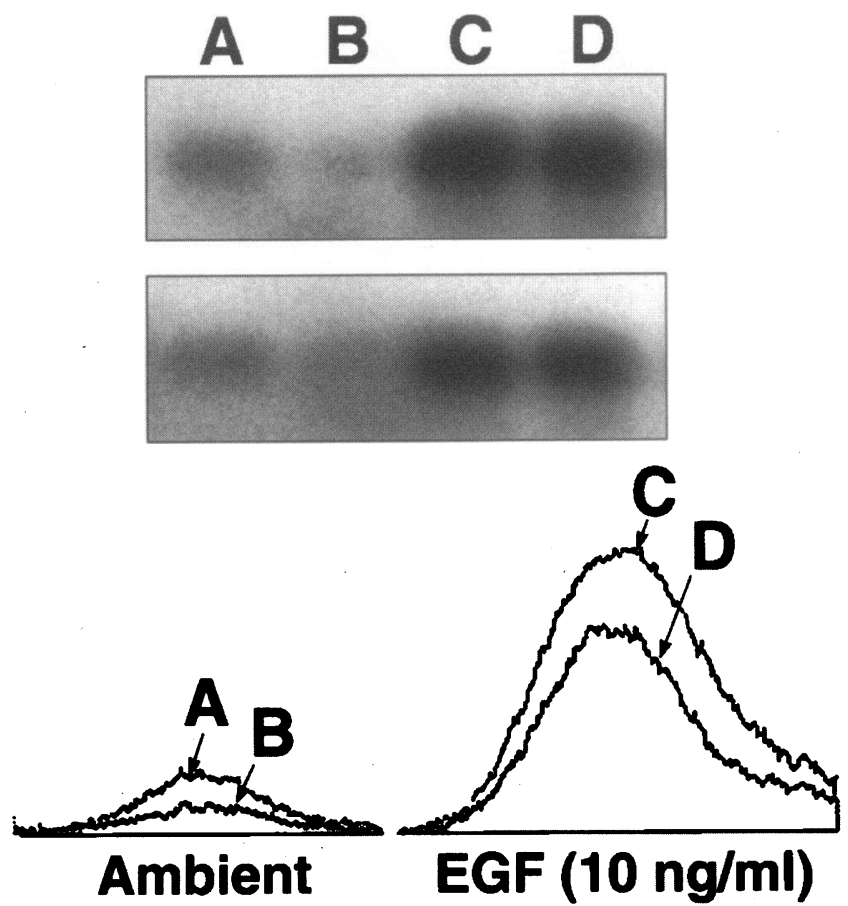

Figure 4. Effects of EGF ( $10 \mathrm{ng} / \mathrm{ml})$ and PDE isozyme inhibitors (10 $\mu \mathrm{M}$ cilostamide (CS) with $10 \mu \mathrm{M}$ rolipram (RP) combined; "CS + RP'") upon activity of mitogen-activated protein kinase (MAPK). For details see Methods. The data are expressed as relative (\%) differences in areas under peak of autoradiograms of spots evaluated by densitometric scanning. Significance of differences was evaluated by paired $t$ test. The cells were incubated without (ambient condition) or with $10 \mathrm{ng} / \mathrm{ml}$ EGF added. Into some wells medium also contained 10 $\mu \mathrm{M}$ cilostamide together with $10 \mu \mathrm{M}$ rolipram. The activity of MAPK was determined as described in Methods. The increase of MAPK $(+\Delta \%)$ in response to EGF was $+321 \pm 50 \%$, mean \pm SEM, $n=16, P$ $<0.01$, paired $t$ test. Change in MAPK activity in response to incubation with PDE inhibitors $(-\Delta \%)$ was in ambient state $-22 \pm 6 \%$, mean \pm SEM ( $n=10, P<0.01)$; and in EGF-stimulated state was $-16 \pm 6 \%$, mean \pm SEM ( $n=17, P<0.02$; paired $t$ test). (Upper panel) Autoradiogram of SDS-PAGE gel showing phosphorylated MBP. A, ambient state; $B$, ambient state with $\mathrm{CS}+\mathrm{RP}$; $C$, with EGF alone; $D$, EGF with CS + RP. The two replicate gels are shown. (Lower panel) Densitometric scan of autoradiogram of ${ }^{32} \mathrm{P}$-phosphorylated MBP. Left, values under ambient conditions without additions $(A)$, or with added $\mathrm{CS}+\mathrm{RP},(B)$. Right, values with EGF alone $(C)$, or with added CS $+\mathrm{RP},(D)$.

glomeruli can be activated only by incubation with antagonists of specific PDE isozyme(s) without stimulation of adenylate cyclase and without detectable increase of cAMP (22), we explored whether inhibition of one or more PDE isozymes present in MC would sufficiently activate the cognate cAMP-PKA pathway to elicit "crosstalk" inhibition of the MAPK regulatory pathway $(12,14-17)$. Indeed, a specific antagonists of PDE-III, "hybrid" antagonist of PDE-III and PDE-IV and, to a much lesser degree antagonists of PDE-IV (Tables I and II) (Fig. 2, 3) suppressed, in micromolar concentrations, mitogenesis of MC, both in the ambient state and when stimulated by cytokines (Tables I and II).

The pattern of PDE isozymes found in MC differs from whole rat glomeruli (22) in that PDE-II, which is abundant in whole glomeruli is not detectable in MC, and that PDE-IV is about two times higher than PDE-III (Fig. 1). Neither in glomeruli (22) nor in cultured MC does PDE-I hydrolyze cAMP, and accepts only cGMP (Fig. 1). Our observation that only antagonists of PDE-III and PDE-IV, but not inhibitors of other PDE isozymes suppress $\left[{ }^{3} \mathrm{H}\right]$ thymidine incorporation is consistent with our analysis of PDE isozymes pattern in MC (Fig. 1).

The antagonist of PDE-III cilostamide and also PDE-III/IV antagonist zardaverine suppressed $\left[{ }^{3} \mathrm{H}\right]$ thymidine incorporation to a similar degree as forskolin or $\mathrm{B}_{2} \mathrm{cAMP}$ (Fig. 2) but unlike forskolin, achieved this effect without measurable increases of cAMP (Table I, Fig. 2). This observation indicates that decreased cAMP hydrolysis by isozyme PDE-III alone, without stimulation of adenylate cyclase, is sufficient to activate PKA in situ (Fig. 3) and to inhibit mitogenesis (Tables I and II and Fig. 3). Inhibition of mitogenesis can be achieved without increase of cAMP (Table I, Fig. 2 and 3 ) and this may suggest that cAMP increases only within a specific compartment of the MC that is needed for activation of PKA that is required for inhibition of $\left[{ }^{3} \mathrm{H}\right]$ thymidine incorporation (Fig. 3). Evidence that intracellular cAMP levels are indeed increased in response to PDE-III inhibitors without detecting change of total cAMP content is provided by in situ activation of PKA (Fig. 3). In situ activation of PKA (25) or increased occupancy of its regulatory subunits (37) are more sensitive indices of enhanced intracellular cAMP (or its redistribution), than measurement cAMP content in the cell extracts $(22,25,37)$. Our other observations on cAMP dynamics (Table III) in MC are also consistent with such an interpretation. Although the PDE-III isozyme is much less abundant in MC than PDE-IV (Fig. 1), cilostamide and other PDE-III inhibitors are severalfold more effective than PDE-IV inhibition by rolipram or denbufylline in decreasing [ ${ }^{3} \mathrm{H}$ ] thymidine incorporation by MC (Tables I and II; Fig. 3). Incubation of MC with cilostamide also activated PKA in situ to significantly higher degree than with rolipram (Fig. 3). Yet, when the rate of cAMP synthesis in MC is stimulated by nonspecific agonist forskolin (Table III) effects of the two PDE isozymes antagonists upon cAMP accumulation were opposite to their effect upon mitogenesis (Table III). This comparison of disparate effects the two PDE isozyme antagonists have upon a specific cellular function, i.e., inhibition of mitogenesis, on one hand (Tables I and II; Fig. 3), and upon overall cAMP metabolism on the other hand (Table III) does suggest that the cAMP pool metabolized by PDE-III is functionally linked to regulation of mitogenesis. These findings, suggesting existence of a PDE-III-related compartment, are in principle similar to observations by Manganiello et al. (38) who found that in adipocytes the cilostamide-sensitive PDE-III rather than PDE-IV is linked to regulation of lipolysis in adipocytes $(38,39)$. Likewise, S. E. Sadler (40) found that only PDE-III inhibitors, but not inhibitors of PDE-IV, injected to Xenopus laevis oocytes block the growth-promoting actions of insulin, IGF-I or p21ras (40). However, it should be also considered that in situ PDEIV may have lower affinity for cAMP than PDE-III.

The notion that a specific cAMP pool metabolized by PDEIII is linked to PKA that inhibits mitogenesis by phosphorylating $\operatorname{Raf}-1(14,16)$ is also compatible with the finding that a minor increase of in situ PKA activity by cilostamide resulted in similar near-maximum inhibition of mitogenesis as the complete PKA activation by forskolin (Fig. 3). The Raf-1 protein 
kinase is inactivated by PKA phosphorylation of $\mathrm{Ser}_{43}$ on the inner side of the cell membrane $(11,13,16)$; conceivably in intact MC PDE-III may be situated close to the plasma membrane. In other cell types, for example, it is membrane-bound PDE-III that specifically regulates lipolysis in adipocytes (38, 39 ), or contractility in cardiac sarcoplasmic reticulum (41); in hepatocytes, PDE-III bound to membrane "dense vesicles"' is specifically related to glucagon and insulin actions (42). In order to detect sometimes fragile association with membrane, a very gentle cell disruption and fractionation ought to be employed (43). Thus, the precise localization of PDE-III within MC needs to be determined in future specifically designed studies.

Stimulation of MAPK activity in MC by EGF affirms the identity of the assayed protein kinase as MAPK (Fig. 4). Both under ambient conditions as well as when stimulated by EGF, PDE isozyme antagonists by decreased MAPK activity (Fig. 4) while PKA activity was significantly increased (Fig. 3). These findings support the notion that PDE antagonists suppress $\left[{ }^{3} \mathrm{H}\right]$ thymidine incorporation via activation of the cAMP-PKA pathway and by inhibiting the mitogen-activated phosphorylation cascade upstream to MAPK and ultimately by decreasing the activity of MAPK $(6,12)$. While the extent of MAPK inhibition was relatively modest (Fig. 4), it should be realized that the employed assay does not distinguish between MAPK isozymes; the decrease in overall MAPK activities may reflect more extensive inhibition of one of the MAPK isozymes (10). PKA was also activated only moderately by PDE inhibitors that suppressed mitogenesis to the same degree as forskolin, which activates PKA completely (Fig. 3) and blunts markedly activity of MAPK in MC (44).

In conclusion, the present study shows that cAMP-PKA signaling pathway has a suppressive rather than a stimulatory effect upon MC proliferation and that the mitogen-activated phosphorylation cascade of these cells is amenable to an indirect inhibition by selective antagonists of PDE isozyme type III (and to lesser degree PDE-IV), both in the ambient state and under stimulation by mitogens. Further, we also show that in micromolar concentrations of a PDE-III antagonist can activate in situ PKA without detectable changes in cAMP content (Fig. 3), and moderate activation of PKA elicits near-maximum inhibition of mitogenesis, as assessed by $\left[{ }^{3} \mathrm{H}\right]$ thymidine incorporation. The pattern of findings points to the possibility that the PDE-IIIregulated cAMP pool is functionally related to PKA activation, phosphorylation and decrease in the activity of Raf-1 protein kinase, which ultimately results in decrease of MAPK activity (Fig. 4).

Previously (22) we found that a specific inhibitor of PDEIV rolipram, via activation of PKA, attenuated formation of reactive oxygen metabolites, another important pathogenic factor causing glomerular injury. Thus, the results of the present as well as of our previous study (22) suggest that PDE isozymes in glomerular cells represent potential novel targets for pharmacologic intervention (45) which, by modulation of the signalling pathways, may block or diminish various types of pathologic processes in glomeruli.

\section{Acknowledgments}

Ms. Deborah C. Melder, Messrs. Michael Thompson, and Henry Walker provided expert technical assistance and Ms. Mary E. Bennett provided excellent secretarial assistance. Mr. Kenneth Offord, M.S., (Department of Biostatistics), provided expert consultation in evaluation of results. We are grateful to Dr. Jack N. Wells (Department of Pharmacology, Vanderbilt University School of Medicine, Nashville, TN) for his generous gift of 8-MeoM-IBMX. Rolipram was a gift of Berlex Laboratories (Cedar Knolls, NJ). Cilostamide and cilostazol were gifts of Otsuka Pharmaceutical Company (Osaka, Japan); Zardaverine was a gift of Dr. C. Schudt (Byk Gulden, Konstanz, Federal Republic of Germany), and denbufylline was gift from Smith, Kline Beecham Pharmaceutical (Worthing, UK).

This study was supported by National Institute of Diabetes and Digestive and Kidney Diseases grant DK-16105, grant DK-45280 and by the Mayo Foundation. Dr. Eduardo N. Chini is a Research Fellow of the Mayo Foundation. Dr. Karel Matousovic, Institute of Clinical and Experimental Medicine, Prague, Czech Republic, was recipient of Fulbright Scholarship.

\section{References}

1. Abboud, H. E. 1993. Growth factors in glomerulonephritis. Kidney Int 43:252-267.

2. Floege, J., E. Eng, B. A. Young, and R. J. Johnson. 1993. Factors involved in the regulation of MC proliferation in vitro and in vivo. Kidney Int. 43:S48S54.

3. Johnson, R. J. 1994. The glomerular response to injury: Progression or resolution? Kidney Int. 45:1769-1782.

4. Abboud, H. E. 1992. Growth factors and the mesangium. J. Am. Soc. Nephrol 2:S185-S189.

5. Cattell, V. 1994. Macrophages in acute glomerular inflammation. Kidney Int. 45:945-952.

6. Nishida, E., and Y. Gotoh. 1993. The MAP kinase cascade is essential for diverse signal transduction pathways. Trends Pharmacol. Sci. 18:128-131.

7. Sadowski, H. B., K. Shuai, J. E. Darnell, Jr., and M. Z. Gilman. 1993. A common nuclear signal transduction pathway activated by growth factor and cytokine receptors. Science (Wash. DC). 261:1739-1744.

8. Iwashita, S., and M. Kobayashi. 1992. Signal transduction system for growth factor receptors associated with tyrosine kinase activity: epidermal growth factor receptor signalling and its regulation. Cell Signalling. 4:123-132.

9. Davis, R. J. 1993. The mitogen-activated protein kinase signal transduction pathway. J. Biol. Chem. 268:14553-14556.

10. Robbins, D. J., E. Zhen, M. Cheng, S. Xu, D. Ebert, C. Garcia, A. Dang, and M. H. Cobb. 1993. Regulation and properties of extracellular signal-regulated protein kinases 1, 2, and 3. J. Am. Soc. Nephrol. 4:1104-1110.

11. Hall, A. 1993. A Biochemical Function for Ras-At Last. Science (Wash. DC). 264:1413-1414.

12. Marx, J. 1993. Two major signal pathways linked. Science (Wash. DC). 262:988-989.

13. Stokoe, D., S. G. MacDonald, K. Cadwallader, M. Symons, and J. F. Hancock. 1994. Activation of Raf as a result of recruitment to the plasma membrane. Science (Wash. DC). 264:1463-1467.

14. Graves, L. M., K. E. Bornfeldt, E. W. Raines, B. C. Potts, S. G. MacDonald, R. Ross, and E. G. Krebs. 1993. Protein kinase A antagonizes platelet-derived growth factor-induced signalling by mitogen-activated protein kinase in human arterial smooth muscle cells. Proc. Natl. Acad. Sci. USA. 90:10300-10304.

15. Sevetson, B. R., X. Kong, and J. C. Lawrence, Jr. 1993. Increasing cAMP attenuates activation of mitogen-activated protein kinase. Proc. Natl. Acad. Sci. USA. 90:10305-10309.

16. Wu, J., P. Dent, T. Jelinek, A. Wolfman, M. J. Weber, and T. W. Sturgill. 1993. Inhibition of the EGF-activated MAP kinase signalling pathway by adenosine 3',5'-monophosphate. Science (Wash. DC). 262:1065-1069.

17. Cook, S. J., and F. McCormick. 1993. Inhibition by cAMP of Ras-dependent activation of Raf. Science (Wash. DC). 262:1069-1072.

18. Frodin, M., P. Peraldi, and E. V. Obberghen. 1994. Cyclic AMP activates the mitogen-activated protein kinase cascade in PC12 cells. J. Biol. Chem. 269:6207-6214.

19. Dumont, J. E., J. C. Jauniaux, and P. P. Roger. 1989. The cyclic AMPmediated stimulation of cell proliferation. Trends Biochem. Sci. 14:67-71.

20. Beavo, J. A., and D. H. Reifsnyder. 1990. Primary sequence of cyclic nucleotide phosphodiesterase isozymes and the design of selective inhibitors. Trends Pharmacol. Sci. 11:150-155.

21. Beavo, J. A., M. Conti, and R. J. Heaslip. 1994. Multiple cyclic nucleotide phosphodiesterases. Mol. Pharmacol. 46:399-405.

22. Chini, C. C. S., E. N. Chini, J. M. Williams, K. Matousovic, and T. P. Dousa. 1994. Formation of reactive oxygen metabolites in glomeruli is suppressed 
by inhibition of cAMP phosphodiesterase isozyme type IV. Kidney Int. 46:2836.

23. Yamaki, M., S. McIntyre, M. E. Rassier, J. H. Schwartz, and T. P. Dousa 1992. Cyclic 3',5'-nucleotide diesterases in dynamics of cAMP and cGMP in rat collecting duct cells. Am. J. Physiol. 262:F957-F964.

24. Bradford, M. M. 1976. A rapid and sensitive method for the quantitation of microgram quantities of protein utilizing the principle of protein dye binding. Anal. Biochem. 72:248-254.

25. Corbin, J. D. 1983. Determination of the cAMP-dependent protein kinase activity ratio in intact tissues. In Methods in Enzymology. vol. 99. J. D. Corbin and J. G. Hardman, editors. Academic Press, Inc., New York. 227-232.

26. Kemp, B. E., H. C. Cheng, and D. A. Walsh. 1988. Peptide inhibitors of cAMP-dependent protein kinase. In Methods in Enzymology. vol. 159, J. D.

Corbin and R. A. Johnson, editors. Academic Press, Inc., San Diego. 173-182.

27. Sugimoto, T., R. Kikkawa, M. Haneda, and Y. Shigeta. 1993. Atria natriuretic peptide inhibits endothelin-1-induced activation of mitogen-activated protein kinase in cultured rat MC. Biochem. Biophys. Res. Commun. 195:72-78.

28. Wang, Y., M. S. Simonson, J. Pouyssegur, and M. J. Dunn. 1992. Endothelin rapidly stimulates mitogen-activated protein kinase activity in rat MC. Biochem. J. 287:589-594.

29. Kincaid, R. L., and V. C. Manganiello. 1988. Assay of cyclic nucleotide phosphodiesterase using radiolabeled and fluorescent substrates. In Methods in Enzymology. J. Corbin and R. Johnson, editors. Academic Press, Inc., California. 457.

30. Rassier, M. E., S. J. McIntyre, M. Yamaki, S. Takeda, J.-T. Lin, and T. P. Dousa. 1991. Isozymes of cyclic-3',5'-nucleotide phosphodiesterases in rena epithelial LLC-PK 1 cells. Kidney Int. 41:88-99.

31. Schudt, C., S. Winder, M. Eltze, U. Kilian, and R. Beume. 1991. Zardaverine: a cyclic AMP specific PDE III/IV inhibitor. Agents Actions. 34:379-402.

32. Wells, J. N., J. E. Garst, and G. L. Kramer. 1981. Inhibition of separated forms of cyclic nucleotide phosphodiesterase from pig coronary arteries by 1,3 disubstituted and 1,3,8-trisubstituted xanthines. J. Med. Chem. 24:954-958.

33. Alvarez, R., G. L. Banerjee, J. J. Bruno, G. L. Jones, K. Littschwager A. M. Strosberg, and M. C. Venuti. 1986. A potent and selective inhibitor of cyclic AMP phosphodiesterase with potential cardiotonic and antithrombotic properties. Mol. Pharmacol. 554-560.

34. Chijiwa, T., A. Mishima, M. Hagiwara, M. Sano, K. Hayashi, T. Inoue, K. Naito, T. Toshioka, and H. Hidaka. 1990. Inhibition of forskolin-induced neurite outgrowth and protein phosphorylation by a newly synthesized selective inhibitor of cyclic AMP-dependent protein kinase, $\mathrm{N}$ - [2-(p-Bromocinnamylamino)ethyl]-5-isoquinolinesulfonamide (H-89), of PC12D pheochromocytoma cells. J. Biol. Chem. 265:5267-5272.
35. Grande, J. P., M. L. Jones, C. L. Swenson, P. D. Killen, and J. S. Warren. 1994. Lipopolysaccharide induces monocyte chemoattractant protein production by rat MC. J. Lab. Clin. Med. 124:112-117.

36. Adams, R. L. P. 1990. The cell cycle. In Laboratory Techniques in Biochemistry and Molecular Biology-Cell Culture for Biochemists. R. H. Burdon and P. H. vanKnippenberg, editors. Elsevier, Amsterdam, Oxford, New York. 187-210.

37. Dufau, M. L., T. Tsuruhara, K. A. Horner, E. Podesta, and K. J. Catt. 1977. Intermediate role of adenosine 3',5'-cyclic monophosphate and protein kinase during gonadotropin-induced steroidogenesis in testicular interstitial cells Proc. Natl. Acad. Sci. USA. 74:3419-3423.

38. Manganiello, V. C., and M. L. Elks. 1986. Regulation of particulate cAMP phosphodiesterase activity in 3T3-L1 adipocytes: The role of particulate phosphodiesterase in the antilipolytic action of insulin. In Mechanisms of Insulin Action. P. Belfrage, J. Donner, and P. Stralfors, editors. Elsevier Science Publishers (Biomedical Division), New York. 147-166.

39. Elks, M. L., and V. C. Manganiello. 1984. Selective effects of phosphodiesterase inhibitors on different phosphodiesterases, adenosine $3^{\prime}, 5^{\prime}$-monophosphate metabolism, and lipolysis in 3T3-L1 adipocytes. Endocrinology. 115:12621268.

40. Sadler, S. E. 1991. Type III phosphodiesterase plays a necessary role in the growth-promoting actions of insulin, insulin-like growth factor-I, and $\mathrm{Ha}$ p21ras in Xenopus laevis oocytes. Mol. Endocrinol. 5:1939-1946.

41. Weishaar, R. E., D. C. Kobylarz-Singer, R. P. Steffen, and H. R. Kaplan. 1987. Subclasses of cyclic AMP-specific phosphodiesterase in left ventricula muscle and their involvement in regulating myocardial contractility. Circ. Res. 61:539-547.

42. Houslay, M. D., and E. Kilgour. 1990. Cyclic nucleotide phosphodiesterases in liver. In Cyclic Nucleotide Phosphodiesterases: Structure, Regulation and Drug Action. J. Beavo and M. D. Houslay, editors. John Wiley \& Sons, England. 185-224.

43. Nicholson, C. D., R. A. J. Challis, and M. Shahid. 1991. Differential modulation of tissue function and therapeutic potential of selective inhibitors of cyclic nucleotide phosphodiesterase isoenzymes. Trends Pharmacol. Sci. 12:1927.

44. Li, X. M., R. W. Schrier, and R. A. Nemenoff. 1994. Growth factor stimulation of MAP kinase is inhibited by prostaglandin $E_{2}$ and forskolin in rat renal MC. J. Am. Soc. Nephrol. 5:696.

45. Giembycz, M. A. 1992. Could isoenzyme-selective phosphodiesterase inhibitors render bronchodilator therapy redundant in the treatment of bronchial asthma? Biochem. Pharmacol. 43:2041-2051. 